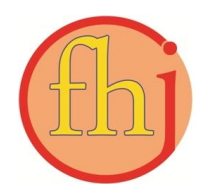

Faletehan Health Journal, 7 (1) (2020) 1-11

www. journal.Ippm-stikesfa.ac.id/ojs/index.php/FHJ

ISSN 2088-673X | e-ISSN 2597-8667

\title{
Pengaruh Latihan Peregangan Perut Terhadap Karakteristik Nyeri Menstruasi Remaja Awal
}

\author{
Andi Saifah ${ }^{1 *}$ \\ ${ }^{1}$ Prodi D-III Keperawatan, Fakultas Kedokteran Universitas Tadulako \\ *Corresponding Author: saifah90@yahoo.co.id
}

\begin{abstract}
Abstrak
Nyeri menstruasi cenderung mengganggu aktifitas sehari-hari dan penampilan akademik pada remaja putri. Latihan peregangan merupakan salah satu intervensi nonfarmakologi dalam mengatasi nyeri. Tujuan penelitian adalah menganalisis pengaruh latihan peregangan perut terhadap perubahan karakteristik nyeri menstruasi remaja awal di SM P Negeri Kecamatan Tatanga Kota Palu. Desain penelitian yang digunakan adalah quasi experimental pre-test dan post test design. Pengambilan sampel secara purposive sampling, masing-masing 41 responden (usia 12-14 tahun dengan nyeri menstruasi) untuk kelompok perlakuan dan kelompok kontrol. Instrument penelitian adalah kuesioner, checklist karakteristik nyeri menstruasi dan booklet panduan latihan. Uji statistik yang digunakan adalah uji Wilcoxon dengan tingkat kemaknaan 95\%. Hasil uji Wilcoxon menunjukkan perbedaan bermakna antara durasi dan radiasi nyeri menstruasi sebelum dan setelah latihan peregangan perut. Tidak ada perbedaan bermakna pada irama dan kualitas nyeri menstruasi $(\rho>0,05)$. Kesimpulan penelitian adalah latihan peregangan perut mempengaruhi penurunan durasi dan radiasi nyeri menstruasi, namun belum berefek maksimal terhadap penurunan irama dan kualitas nyeri menstruasi.
\end{abstract}

Kata Kunci: Nyeri Menstruasi, Peregangan Perut, Remaja Awal

\section{Effects of Stomach Stretching Exercises Against the Characteristics of Early Adolescent M enstrual Pain}

\begin{abstract}
Menstrual pain tends to interfere with daily activities and academic appearance in teenage girls. Stretching exercise is one of the nonpharmacological interventions in dealing with pain. The main purpose of this research was to analyze the effect of abdominal stretching exercise on the characteristics of painful menstruation in early adolescents at SM $P$ Negeri Subdistrict of Palu City. The design of this study was a quasi-experimental pre-test and post-test design. The sample was obtained by using purposive sampling with 41 respondents involved (between 12-14 years old with painful menstruation) for the treatment group and control group. The instrument used in this study was a questionnaire, characteristics of painful menstrual checklist and exercise guide booklet. Statistic test used the Wilcoxon test by $95 \%$ of a significant level. The Wilcoxon test shows that are significant difference on duration and radiation of painful menstruation before and after abdominal stretching. There is no significant difference in rhythm and menstruation painful quality ( $\rho>0.05)$. Based on the result, it can be concluded that abdominal stretching exercises affect the decrease of duration and radiation of painful menstruation, it has not yet an effect on rhythm and menstruation painful quality.
\end{abstract}

Keywords: Abdominal Stretching, Painful M enstruation, Early Adolescents 


\section{Pendahuluan}

Nyeri menstruasi (dysmenorrhoea) merupakan salah satu masalah kesehatan reproduksi pada remaja putri. Dysmenorrhoea dimulai pada 6-12 bulan pertama setelah menarke dan lebih umum sebelum usia 20 tahun (Sinclair, 2010). Dysmenorrhoea berlangsung rata-rata 1-3 hari, 12-24 jam sebelum onset menstruasi sampai hari kedua (Lewis et all, 2011; Osayande \& Mehulic, 2014).

Kejadian dysmenorrhoea di berbagai negara cukup tinggi yaitu diatas 30\%. Diperkirakan 43\%90\% dysmenorrhoea pada remaja di Amerika (Unzal et al,2010). Hasil penelitian Gulzar et al (2015) terhadap 337 pelajar perempuan (12-19 tahun) di Karachi Pakistan, dilaporkan $78 \%$ yang mengalami dysmenorrhoea, 70,2\% dari 1000 perempuan Indian (12-28 tahun) di India Selatan (Omidvar et al, 2015). Kejadian dysmenorrhoea di Indonesia sebesar 54,89\% (Proverawati \& Maisaroh, 2009). Hasil survey pada siswi SMP di Kecamatan Tatanga Kota Palu, ditemukan 138 orang $(37,07 \%)$ mengalami dysmenorrhoea primer.

Dysmenorrhoea mempunyai gejala utama dan gejala tambahan. Gejala utama dysmenorrhoea adalah nyeri atau kram perut bagian bawah dan pelvis, sering menjalar ke paha, punggung atas dan bawah. Keluhan lain seperti mual, muntah, nyeri kepala, diare, keletihan, hipersensitif terhadap suara, cahaya dan sentuhan, disorientasi, pusing, dan sinkop (Sinclair, 2010; Lewis et al, 2011; Osayande, 2014). Ketidaknyamanan tersebut akan berdampak pada aktivitas sehari-hari, penampilan akademik dan kualitas hidup remaja. 91,3\% dari 1000 responden mengalami keluhan dysmenorrhoea, 48,3\% absensi sekolah selama 1-3 hari (Omidvar et al, 2015); 60,4\% (337 remaja) aktivitas rutin terganggu dan $40 \%$ tidak hadir di sekolah (Gulzar et al, 2015); 51\% absen dari sekolah atau tempat kerja karena dysmenorrhoea di Turki (Ozerdogan, 2009). Keluhan dan dampak tersebut akan mempengaruhi pada penurunan kualitas hidup para remaja putri, sehingga pencegahan atau treatment sedini mungkin sangat penting.

Penanganan dysmenorrhoea dapat diatasi dengan farmakologi (obat) dan nonfarmakologi (tanpa obat). Terapi pengobatan dasar dysmenorrhea adalah golongan nonstreoidal anti inflammatory drugs (NSAIDs) sebagai tindakan kolaboratif (Lewis et al, 2011). Penggunaan obat medis kimiawi sangat efektif mengurangi atau menghilangkan $80 \%$ keluhan saat menstruasi (Sinclair, 2010), namun obat medis juga dapat menimbulkan efek samping yang merugikan terhadap sistem tubuh lain bagi mereka yang tidak cocok seperti masalah pada lambung jika digunakan dalam waktu lama. Selain itu pengobatan medis juga membutuhkan dana.

Intervensi keperawatan berupa terapi nonfarmakologik efektif untuk mengatasi masalah nyeri. Nursing Intervention Classification (NIC) merekomendasikan untuk menyelesaikan masalah keperawatan nyeri akut dengan terapi aktifitas antara lain latihan peregangan (Bulechek et al, 2013). Dysmenorrhoea primer dapat diatasi dengan regular exercise (latihan teratur), bahkan dysmenorrhoea sekunder terbantu dengan latihan tersebut (Lewis et al, 2011; Sinclair, 2010; Berman \& Snyder, 2012). Latihan peregangan mudah dilakukan dan tidak mengeluarkan biaya. Gerakan latihan untuk mengurangi dysmenorrhoea melibatkan peregangan (stretching) otot-otot perut, pelvis dan paha (Karampour, 2012). Thermacare (2010) menjelaskan salah satu solusi mengatasi dysmenorrhoea adalah Abdominal Stretching Exercise (latihan peregangan perut) karena meningkatkan kebugaran, relaksasi fisik, mengurangi ketegangan otot/nyeri otot (kram), dan mengurangi nyeri saat menstruasi. Beberapa literatur menjelaskan tentang efek positif latihan terhadap dysmenorrhoea yaitu menyebabkan pengeluaran endorphin dari otak yang berfungsi sebagai analgesic alami (Sinclair, 2010; Sherwood, 2012).

Hasil riset menunjukkan intensitas dysmenorrhoea menurun pada kelompok eksperimen usia 18-25 tahun setelah diberikan latihan peregangan selama 4 bulan, meskipun tidak memperlihatkan nilai signifikan $(\rho)$, hanya menggunakan nilai mean dan standar deviasi (Rajalaxmi et al, 2016). Latihan peregangan efektif menurunkan intensitas nyeri dysmenorrhoea primer pada kelompok eksperimen selama 4 minggu (6 hari/minggu, 2 kali/hari) dengan nilai $\rho<0,001$ (Gamit, Sheth \& Vyas, 2014). Skala nyeri menurun secara bermakna $(\rho<0,00)$ setelah melakukan senam dysmenorrhoea selama 3-5 hari sebelum haid 
Faletehan Health Journal, 7 (1) (2020) 1-11 www. journal.Ippm-stikesfa.ac.id/ojs/index.php/FHJ ISSN 2088-673X | 2597-8667

pada 12 orang siswa SMA Negeri 2 Padang (Deharnita, Sumarni \& Widia, 2014).

Beberapa hasil riset tentang latihan fisik peregangan dapat menurunkan intensitas nyeri menstruasi, namun analisis tentang karakteristik nyeri yang lain seperti durasi, radiasi, kualitas dan irama nyeri menstruasi dengan responden pada remaja awal (usia 12-14 tahun) masih sangat kurang ditemukan peneliti. Tujuan penelitian ini adalah menganalisis pengaruh latihan peregangan perut terhadap karakteristik nyeri menstruasi (durasi, radiasi, kualitas, irama) pada remaja awal di SMP Kecamatan Tatanga Kota Palu.

\section{Metode Penelitian}

Penelitian ini telah lolos uji etik dari Komite Etik Fakultas Kedokteran Universitas Tadulako pada tanggal 04 Agustus 2017, Nomor: 6278/UN 28.1.30/KL/2017. Desain yang digunakan dalam penelitian ini adalah quasy experimental yang melibatkan dua kelompok yaitu kelompok perlakuan (yang diberikan latihan peregangan perut) dan kelompok kontrol (tidak diberikan perlakuan). Kedua kelompok subjek diukur karakteristik nyeri menstruasi sebelum dan setelah diberi perlakuan. Penelitian ini dilakukan pada bulan Agustus - Oktober 2017.

Populasi penelitian adalah seluruh siswi yang mengalami nyeri menstruasi di SMP Negeri Kecamatan Tatanga Palu. Kelompok perlakuan adalah siswi SMPN 5 karena fasilitas memadai dan dukungan tinggi dari sekolah, kelompok kontrol adalah siswi SMPN 11. Cara pengambilan sampel adalah purposive sampling dengan kriteria bersedia menjadi responden (diberi informed consent), usia 12-14 tahun, dysmenorrhoea primer. Jumlah sampel sebanyak 82 responden,

Instrumen yang digunakan untuk latihan peregangan perut adalah booklet, dikembangkan oleh peneliti sebagai panduan yang dibagikan ke subyek kelompok perlakuan dan bola plastik sebagai alat bantu pada gerakan ke-5. Booklet berisi tentang konsep dysmenorrhoea dan tata cara latihan peregangan perut yang mengacu pada teori. Latihan peregangan perut terdiri dari enam langkah (Themacare, 2010) yaitu:

1) gerakan cat stretch (Posisi awal: letakkan tangan dan lutut di lantai, tangan sejajar bahu, lutut sejajar pinggul, kaki rileks, mata menatap ke lantai. Lengkungkan punggung, perut di arahkan mendekati lantai senyaman mungkin.Tegakkan dagu dan mata menatap
lantai.Tahan selama 10 detik, sambil hitung dengan bersuara kemudian rileks. Punggung digerakkan keatas, kepala menunduk ke lantai. Tahan selama 10 detik, sambil hitung dengan bersuara kemudian rileks. Duduk diatas tumit, rentangkan tangan kedepan sejauh mungkin. Tahan selama 20 detik, hitung bersuara kemudian rileks. Latihan dilakukan tiga kali ;

2) lower trunk rotation (Posisi awal: berbaring terlentang, lutut ditekuk, kaki dilantai, kedua lengan dibentangkan keluar. Putar perlahan lutut ke kanan sedekat mungkin dengan lantai, pertahankan bahu tetap dilantai. Tahan 20 detik kemudian hitung bersuara. Putar perlahan lutut ke kiri sedekat mungkin dengan lantai pertahankan bahu tetap dilantai. Tahan 20 detik kemudian hitung bersuara, kemudian kembali ke posisi awal. Latihan dilakukan tiga kali;

3) gerakan buttock/hip stretch(Posisi awal: berbaring terlentang dengan lutut di tekuk. Letakkan bagian luar pergelangan kaki kanan pada paha kiri diatas lutut. Pegang bagian belakang paha kemudian tarik kearah dada senyaman mungkin. Tahan selama 20 detik, hitung bersuara, kemudian kembali ke posisi awal dengan rileks. Latihan dilakukan tiga kali;

4) gerakan abdominal strengthening curl up (Posisi awal: berbaring terlentang, lutu ditekuk, kaki dilantai, tangan di bawah kepala. Lengkungkan punggung dari lantai dan dorong kearah langit-langit.Tahan selama 20 detik, hitung bersuara.Ratakan punggung sejajar lantai dengan mengencangkan otot-otot perut dan bokong.Lengkungkan sebagian tubuh bagian atas ke arah lutut.Tahan selama 20 detik, hitung bersuara. Latihan dilakukan tiga kali;

5) gerakan lower abdominal strengthening (Posisi awal: berbaring terlentang, lutut ditekuk, lengan di bentangkan sebagian keluar. Letakkan bola antara lutut dan bokong. Ratakan punggung bawah kelantai dengan mengencangkan otot-otot perut dan bokong. Perlahan tarik kedua lutut kearah dada, sambil menarik tumit dan bola, kencangkan otot bokong, jangan melengkungkan punggung. Latihan dilakukan 15 kali;

6) gerakan the bridge position (Posisi awal: berbaring terlentang, lutut ditekuk, kaki dan siku dilantai, lengan dibentangkan sebagian 
keluar. Ratakan punggung dilantai dengan mengencangkan otot-otot perut dan bokong. Angkat pinggul dan punggung bawah untuk membentuk garis lurus ke dada. Tahan selama 20 detik, sambil dihitung dengan bersuara, kemudian perlahan ke posisi awal dan rileks. Latihan dilakukan tiga kali.

Instrumen untuk mengidentifikasi karakteristik demografi (usia, kelas, nomor kontak, alamat, tanggal menstruasi terakhir, lama dan siklus menstruasi) menggunakan kuesioner. Instrument karakteristik nyeri menstruasi adalah lembar cheklist (mulai 24 jam sebelum menstruasi sampai selesai) terdiri dari: 1) Durasi (berapa hari nyeri menstruasi); 2) Radiasi (jumlah dan jenis area penyebaran nyeri: kemaluan, bokong, paha, punggung, dan lain-lain); 3) Irama (hilangtimbul= skore 1 , terus menerus $=$ skore 2$) ; 4$ ) Kualitas (jumlah dan jenis sensasi: ditusuk, ditekan, diiris, terbakar, diremuk, dan lain-lain). Instrument dikembangkan oleh peneliti berdasarkan konsep teori nyeri dan dysmenorrhoea. Uji coba instrumen telah dilaksanakan pada 20 responden di SMP Negeri 3 Palu yang memiliki karakteristik yang sama dengan responden penelitian. Nilai $r=0,491-$ 0,708 (valid jika nilai $r>0,444$ ), nilai reliabilitas alpha Crombach 0,743.

Peneliti dan guru UKS bekerja sama dalam persiapan ruangan dan pelaksanaan latihan. Kelompok perlakuan diberi penjelasan tentang kuesioner dan latihan, selanjutnya dilatih sampai menguasai gerakan dengan benar selama tiga hari. Peneliti mengidentifikasi waktu siklus menstruasi responden dan membagikan kuesioner dan lembar cheklist menjelang masa menstruasi pada kedua kelompok. Responden tidak diperkenankan untuk minum obat pereda nyeri atau obat herbal selama penelitian.

Pengukuran pertama (pre tes) dilakukan pada 24 jam sebelum menstruasi terakhir sampai selesai menstruasi, selanjutnya pada hari ke-4 menstruasi diberi latihan peregangan perut sampai hari ke-3 siklus mensruasi berikutnya pada kelompok perlakuan. Intervensi diberikan mengikuti siklus menstruasi setiap responden. Latihan dilakukan setiap hari di sekolah pada jam istirahat sekitar jam 10.00-10.30 wita, jika hari libur maka latihan tetap dilakukan di sekolah dimulai jam 08.30 sampai selesai

Pengukuran kedua (pasca tes) dilakukan pada menstruasi bulan berikutnya (24 jam sebelum menstruasi sampai selesai) pada semua responden. Data dianalisis secara univariat dan bivariat menggunakan uji Wilcoxon (sebaran data tidak berdistribusi normal) dengan tingkat kemaknaan $\rho<0,05$ (Dahlan, 2015).

\section{Hasil dan Pembahasan \\ Karakteristik Responden}

Pada tabel 1 menunjukkan bahwa distribusi responden berdasarkan usia paling banyak usia 14 tahun sebanyak 50 responden $(61,73 \%)$, durasi menstruasi paling banyak pada rentang 4-6 hari sebanyak 46 responden (56,79\%), siklus menstruasi paling banyak pada siklus kurang dari 28 hari sebanyak 42 responden $(51,85 \%)$.

Karakteristik responden yang dibahas adalah usia, durasi dan siklus menstruasi. Usia responden ditemukan lebih dari sebagian berusia 14 tahun. Hasil ini sejalan dengan hasil penelitian Argawal \& Venkeat (2009) pada responden usia 12-15 tahun yang mengalami nyeri menstruasi, proporsi tertinggi pada usia 14 tahun sebesar $62,7 \%, 15$ tahun $(62,4 \%), 13$ tahun (47,2\%) 12 tahun $(43,6 \%)$. Kazama et al (2015) juga melakukan survey pada 1.018 remaja usia 12-15 tahun, ditemukan remaja yang mengalami nyeri menstruasi $55 \%$ berusia 15 tahun dan $50,3 \%$ berusia 14 tahun.

Durasi mentruasi pada kedua kelompok terbanyak pada rentang 4-6 hari. Fase haid (menstruasi) ditandai dengan pengeluaran darah dan sisa endomentrium dari vagina, biasanya berlangsung 4-6 hari (Lewis et al, 2001) atau 5-7 hari (Sherwood, 2012). Gulzar et al (2015) menemukan $64,7 \%$ lama menstruasi dengan ratarata 5-7 hari.

Siklus menstruasi responden terbanyak pada siklus kurang dari 28 hari.Hal ini terjadi karena responden dalam penelitian ini adalah remaja awal.Lewis et al (2011) mengatakan bahwa remaja awal mempunyai siklus menstruasi yang tidak teratur, peningkatan hormon estrogen dan progesterone tanpa siklus ovulasi.Siklus normal menstruasi rata-rata 28 hari, meskipun rentang siklus menstruasi antara 20-40 hari (Sherwood, 2012; Lewis et al, 2011). Hasil penelitian ini tidak sejalan dengan beberapa hasil studi yang menjelaskan bahwa nyeri menstruasi (primer) lebih banyak terjadi pada individu yang memiliki siklus haid panjang (> 30 hari) (Kural et al, 2015; Sinclair, 2010), meskipun tidak ditemukan 
Faletehan Health Journal, 7 (1) (2020) 1-11 www. journal.Ippm-stikesfa.ac.id/ojs/index.php/FHJ ISSN 2088-673X | 2597-8667

hubungan bermakna antara siklus menstruasi dengan nyeri menstruasi (Kural et al, 2015).

\section{Karakteristik Nyeri Menstruasi Pra dan Paska Latihan Peregangan Perut}

Pada tabel 2 menunjukkan semua karakteristik nyeri menstruasi mengalami penurunan proporsi (perubahan ke arah yang lebih buruk) pada kelompok perlakuan setelah diberi latihan peregangan perut, sedangkan pada kelompok kontrol terjadi sebaliknya. Perubahan pada kelompok perlakuan yaitu persentase durasi nyeri $\geq 7$ hari mengalami penurunan dari $19,51 \%$ menjadi $4,88 \%$, durasi $4-6$ hari $26,83 \%$ menjadi $7,32 \%$. Perubahan durasi nyeri menstruasi terbanyak pada durasi $\leq 3$ hari dari $53,86 \%$ menjadi $87,89 \%$. Sedangkan pada kelompok kontrol durasi nyeri 4-6 hari mengalami peningkatan proporsi, durasi nyeri $\leq 3$ hari mengalami penurunan proporsi.

Hasil penelitian juga menunjukkan bahwa urutan proporsi tertinggi radiasi (penyebaran) nyeri menstruasi sebelum latihan adalah satu area $(48,80 \%)$, dua area $(46,30 \%)$, tiga dan empat area masing-masing 2,4\%. Perubahan proporsi terjadi setelah latihan peregangan perut yaitu $22 \%$ tidak ada penyebaran area nyeri, sebagian besar penyebaran nyeri ke satu area $(75,6 \%)$, hanya 1 responden yang penyebaran dua area $(2,4 \%)$. Penyebaran area nyeri tertinggi di area kemaluan sebesar $56,10 \%$ pada kelompok perlakuan, sedangkan pada kelompok kontrol proporsi tertinggi radiasi area nyeri di bokong $(63,41 \%)$. Hasil penelitian tentang irama nyeri menstruasi adalah mayoritas berirama hilang timbul pada kedua kelompok responden baik sebelum maupun setelah latihan peregangan perut yaitu $82,9 \%$ menjadi $100 \%$.

Kedua kelompok responden mempunyai kualitas nyeri menstruasi, mayoritas pada satu sensasi saja berkisar 90,2\% - 92,7\% dan terbanyak pada jenis sensasi seperti ditusuk-tusuk antara $43,9 \%$ - 68,29\%. Latihan peregangan perut cenderung mengurangi jenis sensasi yang dirasakan pada kelompok perlakuan yaitu tidak ditemukan jenis sensasi seperti teriris dan terbakar.

\section{Perbedaan Karakteristik Nyeri Menstruasi Durasi Nyeri Menstruasi}

Berdasarkan tabel 3 menunjukkan nilai uji Wilcoxon $\rho=0,001$ yang berarti terdapat perbedaan yang bermakna durasi nyeri menstruasi sebelum dan setelah diberi latihan peregangan perut. Durasi nyeri menstruasi lebih banyak mengalami penurunan pada kelompok perlakuan sebanyak 23 responden $(56,10 \%), 18$ menetap $(43,90 \%)$, tidak ada yang meningkat, sebaliknya terjadi peningkatan durasi nyeri menstruasi pada kelompok kontrol sebanyak 15 responden $(36,59 \%), 21$ menetap $(51,22 \%)$ dan 5 menurun $(12,19 \%)$.

Tabel 1. Distribusi Frekuensi Karakteristik Responden Menurut Kelas, Usia, Durasi dan Siklus Menstruasi Remaja Awal ( $\mathrm{n}=82)$

\begin{tabular}{lcccc}
\hline \multirow{2}{*}{ Karakteristik } & \multicolumn{2}{c}{ Kelompok Perlakuan } & \multicolumn{2}{c}{ Kelompok Kontrol } \\
\cline { 2 - 5 } & $\mathbf{n}$ & $\mathbf{\%}$ & $\mathbf{n}$ & $\mathbf{\%}$ \\
\hline Kelas & & & & \\
$\quad$ VII & 27 & $\mathbf{6 5 , 8 5}$ & 13 & 31,70 \\
$\quad$ VIII & 14 & 34,15 & 28 & $\mathbf{6 8 , 3 0}$ \\
\hline Usia & & & & \\
$\quad$ 12 tahun & 4 & 9,76 & - & - \\
13 tahun & 15 & 36,58 & 13 & 31,70 \\
$\quad$ 14 tahun & 22 & $\mathbf{5 3 , 6 6}$ & 28 & $\mathbf{6 8 , 3 0}$ \\
\hline Durasi & & & & \\
$\quad$ 4 hari & 1 & 2,44 & 2 & 4,88 \\
$\quad$ 4-6 hari & 21 & $\mathbf{5 1 , 2 2}$ & 25 & $\mathbf{6 0 , 9 7}$ \\
$>$ 7 hari & 19 & 46,34 & 14 & 34,15 \\
\hline Siklus Menstruasi & & & & \\
$\quad<28$ hari & 26 & $\mathbf{6 3 , 4 1}$ & 16 & $\mathbf{3 9 , 0 2}$ \\
28-30 hari & 5 & 12,20 & 14 & 34,15 \\
$\quad$ 30 hari & 10 & 24,39 & 11 & 26,83 \\
\hline Jumlah & 41 & 100 & 41 & 100 \\
\hline
\end{tabular}


Berdasarkan tabel 3 hasil uji Wilcoxon $(\rho=$ $0,001)$ menunjukkan secara statistik terdapat perbedaan bermakna radiasi nyeri menstruasi sebelum dan setelah diberi latihan peregangan perut, sedangkan pada kelompok kontrol nilai $\rho=0,21$,yang berarti tidak ada perbedaan bermakna. Sebagian besar pada kelompok perlakuan mengalami penurunan area radiasi (penyebaran) nyeri menstruasi yaitu sebanyak 29 responden (70,73\%), 12 menetap $(29,27 \%)$, tidak ada yang bertambah, sedangkan pada kelompok kontrol lebih banyak mengalami radiasi nyeri menstruasi yang menetap sebanyak 24 responden $(58,56 \%), 11$ meningkat $(26,83 \%)$ dan hanya enam responden $(14,63 \%)$ berkurang. Radiasi (penyebaran) area nyeri tertinggi di area kemaluan sebesar $56,10 \%$ (pra) menjadi $36,59 \%$ (paska) pada kelompok perlakuan, sedangkan pada kelompok kontrol proporsi tertinggi radiasi area nyeri pada bokong sebesar $63,41 \%$ (pra) dan $51,22 \%$ (paska)

Tabel 2. Distribusi Frekuensi Karakteristik Nyeri Menstruasi menurut Durasi, Radiasi, Irama dan Kualitas Pada Remaja Awal Pra dan Paska Latihan Peregangan Perut ( $\mathrm{n}=82$ )

\begin{tabular}{|c|c|c|c|c|c|c|c|c|}
\hline \multirow{3}{*}{$\begin{array}{c}\text { Karakteristik } \\
\text { Nyeri } \\
\text { Menstruasi } \\
\end{array}$} & \multicolumn{4}{|c|}{ Kelompok Perlakuan } & \multicolumn{4}{|c|}{ Kelompok Kontrol } \\
\hline & \multicolumn{2}{|c|}{ Pra } & \multicolumn{2}{|c|}{ Paska } & \multicolumn{2}{|c|}{ Pra } & \multicolumn{2}{|c|}{ Paska } \\
\hline & $\mathbf{n}$ & $\%$ & $\mathbf{n}$ & $\%$ & $\mathbf{n}$ & $\%$ & $\mathbf{n}$ & $\%$ \\
\hline \multicolumn{9}{|l|}{ Durasi } \\
\hline$\leq 3$ hari & 22 & 53,66 & 36 & 87,80 & 27 & 65,85 & 19 & 46,34 \\
\hline 4-6 hari & 11 & 26,83 & 3 & 7,32 & 14 & 34,15 & 22 & 53,66 \\
\hline$\geq 7$ hari & 8 & 19,51 & 2 & 4,88 & - & - & - & - \\
\hline \multicolumn{9}{|l|}{ Radiasi } \\
\hline Tdk ada & - & - & 9 & 22 & 6 & 14,6 & 4 & 9,8 \\
\hline 1 area & 20 & 48,80 & 31 & 75,60 & 27 & 65,9 & 26 & 63,4 \\
\hline 2 area & 19 & 46,30 & 1 & 2,40 & 7 & 17,1 & 10 & 24,4 \\
\hline 3 area & 1 & 2,40 & - & - & 1 & 2,4 & 1 & 2,4 \\
\hline 4 area & 1 & 2,40 & - & - & - & - & - & - \\
\hline \multicolumn{9}{|l|}{ Jenis Area } \\
\hline Kemaluan & 23 & 56,10 & 15 & 36,59 & 8 & 19,51 & 14 & 34,15 \\
\hline Bokong & 18 & 43,90 & 8 & 19,51 & 26 & 63,41 & 21 & 51,22 \\
\hline Punggung & 17 & 41,46 & 11 & 26,83 & 13 & 31,7 & 16 & 39,02 \\
\hline Paha & 6 & 14,63 & 6 & 14,63 & 3 & 7,3 & 7 & 17,07 \\
\hline \multicolumn{9}{|l|}{ Irama } \\
\hline $\begin{array}{l}\text { Hilang-timbul } \\
\text { (skore 1) }\end{array}$ & 40 & 97,6 & 41 & 100 & 34 & 82,9 & 36 & 87,8 \\
\hline $\begin{array}{l}\text { Terus- } \\
\text { menerus } \\
\text { (skore 2) }\end{array}$ & 1 & 2,4 & - & - & 7 & 17,1 & 5 & 12,2 \\
\hline \multicolumn{9}{|l|}{ Kualitas } \\
\hline 1 sensasi & 37 & 90,2 & 38 & 92,7 & 38 & 92,7 & 37 & 90,2 \\
\hline 2 sensasi & 3 & 7,3 & 1 & 2,4 & 2 & 4,9 & 2 & 4,9 \\
\hline 3 sensasi & 1 & 2,4 & 2 & 4,9 & 1 & 2,4 & 2 & 4,9 \\
\hline \multicolumn{9}{|l|}{ Jenis Sensasi } \\
\hline Ditusuk & 25 & 60,98 & 28 & 68,29 & 21 & 51,22 & 18 & 43,90 \\
\hline Ditekan & 10 & 24,39 & 14 & 66,67 & 4 & 9,76 & 11 & 26,83 \\
\hline Diiris & 1 & 2,44 & - & - & 4 & 9,76 & 4 & 9,76 \\
\hline Terbakar & 4 & 9,76 & - & - & 1 & 2,44 & 3 & 7,32 \\
\hline Diremuk & 6 & 14,63 & 4 & 9,76 & 11 & 26,83 & 11 & 26,83 \\
\hline Total & 41 & & 41 & & 41 & & 41 & \\
\hline
\end{tabular}


Faletehan Health Journal, 7 (1) (2020) 1-11 www. journal.Ippm-stikesfa.ac.id/ojs/index.php/FHJ ISSN 2088-673X | 2597-8667

Pada tabel 3 menunjukkan Uji Wilcoxon tidak ditemukan perbedaan bermakna irama nyeri menstruasi sebelum dan setelah latihan peregangan perut pada kedua kelompok, masingmasing nilai $\rho=0,317$ dan 0,480 . Pada kelompok perlakuan hanya 1 subjek $(2,44 \%)$ yang menurun irama nyeri menstruasi, 40 menetap (97,56\%), sedangkan pada kelompok kontrol terdapat 5 subjek $(12,20 \%)$ irama menstruasi menurun, 33 menetap (80,49), 3 meningkat $(7,32 \%)$

Berdasarkan tabel 3, hasil uji Wilcoxon pada kedua kelompok adalah nilai $\rho>0,05$ yang berartitidak terdapat perbedaan kualitas nyeri menstruasi yang bermakna sebelum dan setelah latihan peregangan perut pada kedua kelompok. Hanya 3 responden $(7,3 \%)$ yang mengalami penurunan kualitas nyeri setelah dilakukan latihan peregangan perut, 35 menetap $(85,37 \%)$ dan 3 meningkat $(7,3 \%)$.

\section{Durasi Nyeri Menstruasi}

Analisis frekuensi menunjukkan lebih dari sebagian durasi nyeri menstruasi $\leq 3$ hari pada kelompok perlakuan. Penurunan drastis persentase durasi 4-6 hari dan $\geq 7$ hari menjadi sebagian besar berdurasi nyeri $\leq 3$ hariterjadi setelah latihan. Sedangkan pada kelompok kontrol terjadi sebaliknya yaitu peningkatan persentase pada durasi 4-6 hari, penurunan persentase pada durasi $\leq 3$ hari. Hasil ini didukung oleh Lewis et al (2011) dan Berman \&Snyder (2012) bahwa nyeri menstruasi terjadi rata-rata tiga hari, sehari sebelum menstruasi sampai hari kedua atau sesaat awitan sampai hari ketiga menstruasi, tetapi dapat terjadi dua hari sebelum awitan dan hilang dalam 2-4 hari atau menjelang akhir menstruasi (Sinclair, 2010).

Tabel 3. Distribusi Perbedaan Karakteristik Nyeri Menstruasi menurut Durasi, Radiasi, Irama dan Kualitas pada Kedua Kelompok Remaja Awal Pra dan Paska Latihan Peregangan Perut (n=82)

\begin{tabular}{|c|c|c|c|c|c|c|}
\hline \multirow{3}{*}{$\begin{array}{l}\text { Karakteristik } \\
\text { Nyeri } \\
\text { menstruasi }\end{array}$} & \multicolumn{3}{|c|}{ Kelompok Perlakuan } & \multicolumn{3}{|c|}{ Kelompok Kontrol } \\
\hline & \multicolumn{2}{|c|}{ Median (Min-Maks) } & \multirow[t]{2}{*}{ Nilai } & \multicolumn{2}{|c|}{ Median (Min-Maks) } & \multirow{2}{*}{ Nilai } \\
\hline & $\operatorname{Pra}(n=41)$ & $\operatorname{Paska}(n=41)$ & & $\operatorname{Pra}(n=41)$ & Paska(n=41) & \\
\hline Durasi & $3(2-8)$ & $3(0-8)$ & $<0,001 *$ & $3(2-6)$ & $4(2-6)$ & $0,011 *$ \\
\hline \multicolumn{4}{|c|}{$\begin{array}{l}\text { Uji Wilcoxon, } 23 \text { subjek }(56,10 \%) \text { durasi nyeri } \\
\text { menstruasi menurun, } 18 \text { menetap }(43,90 \%) \text {, tidak ada } \\
\text { meningkat }\end{array}$} & \multicolumn{3}{|c|}{$\begin{array}{l}15 \text { subjek }(36,59 \%) \text { durasi nyeri } \\
\text { menstruasi meningkat, } 21 \text { menetap } \\
(51,22 \%), 5 \text { menurun }(12,19 \%)\end{array}$} \\
\hline Radiasi & $2(1-4)$ & $1(0-2)$ & $<0,001 *$ & $1(0-3)$ & $1(0-4)$ & 0,291 \\
\hline \multicolumn{4}{|c|}{$\begin{array}{l}\text { Uji Wilcoxon, } 29 \text { subjek area radiasi nyeri menstruasi } \\
\text { berkurang }(70,73 \%), 12 \text { menetap }(29,27 \%) \text {, tidak ada } \\
\text { yang bertambah }\end{array}$} & \multicolumn{3}{|c|}{$\begin{array}{l}6 \text { subjek radiasi nyeri menstruasi } \\
\text { berkurang }(14,63 \%), 24 \text { menetap } \\
(58,56 \%), 11 \text { meningkat }(26,83 \%)\end{array}$} \\
\hline Irama & $1(1-2)$ & & 0,317 & $1(1-2)$ & $1(1-2)$ & 0,480 \\
\hline \multicolumn{4}{|c|}{$\begin{array}{l}\text { Uji Wilcoxon, hanya } 1 \text { subjek }(2,44 \%) \text { yang menurun } \\
\text { irama nyeri menstruasi, } 40 \text { menetap }(97,56 \%)\end{array}$} & \multicolumn{3}{|c|}{$\begin{array}{l}5 \text { subjek }(12,20 \%) \text { irama menstruasi } \\
\text { menurun, } 33 \text { menetap }(80,49), 3 \\
\text { meningkat }(7,32 \%)\end{array}$} \\
\hline Kualitas & $1(1-3)$ & $1(1-3)$ & 1,000 & $1(1-3)$ & $1(1-4)$ & 0,180 \\
\hline \multicolumn{4}{|c|}{$\begin{array}{l}\text { Uji Wilcoxon, } 3 \text { subjek }(7,32 \%) \text { menurun kualitas } \\
\text { (jumlah sensasi nyeri), } 35 \text { tetap }(85,36 \%), 3 \text { meningkat } \\
(7,32 \%)\end{array}$} & \multicolumn{3}{|c|}{$\begin{array}{l}1 \text { subjek menurun kualitas }(2,44 \%) \text {, } \\
36 \text { tetap }(87,80 \%), 4 \text { meningkat } \\
(9,76 \%)\end{array}$} \\
\hline
\end{tabular}

Keterangan : * bermakna/signifikan 
Studi yang mendukung hasil penelitian ini antara lain survey Kural et al (2015) terhadap 310 responden (18-25 tahun) terkait durasi nyeri menstruasi menemukan $92,2 \%$ mengalami nyeri menstruasi maksimal tiga hari. Survey Odmivar et al (2015) pada 1000 wanita Indian di Iran juga menemukan hasil prevalensi tertinggi durasi nyeri menstruasi $\leq 3$ hari yaitu $94 \%$ serta ditemukan hubungan bermakna antara durasi dan intensitas nyeri menstruasi $(\rho=0,000)$, semakin panjang durasi nyeri cenderung semakin berat nyeri menstruasi. Proses fisiologi nyeri menstruasi diawali sejak kadar estrogen dan progesterone turun tajam, peristiwa ini terjadi sebelum (12-24 jam) atau segera setelah awitan aliran menstrual dan berlanjut selama 48 jam hingga 72 jam. Penurunan tajam kadar hormon ovarium (estrogen dan progesterone) merangsang pembebasan prostaglandin. Kontraksi uterus terlalu kuat akibat produksi berlebihan prostaglandin menyebabkan $\mathrm{kram} /$ nyeri menstruasi atau dysmenorrhoea (Sherwood, 2012; Lewis et al, 2011)

Pada uji hubungan ditemukan terdapat perbedaan durasi nyeri menstruasi yang bermakna sebelum dan setelah latihan peregangan perut antara kelompok perlakuan dan kelompok kontrol. Fakta ini menunjukkan latihan peregangan perut mempunyai pengaruh positif dalam menurunkan durasi (hari) nyeri menstruasi pada kelompok perlakuan, dibuktikan dengan $56,10 \%$ menurun, $43,90 \%$ tetap dan tidak ada yang meningkat. Sebaliknya, kelompok yang tidak melakukan latihan peregangan perut terjadi peningkatan durasi nyeri $36,59 \%$ dan tidak terjadi perubahan durasi nyeri menstruasi sebesar 51,22\%. Hasil penelitian didukung oleh penelitian Shahr-jerdy et al (2012) menyatakan bahwa latihan peregangan efektif mengurangi durasi nyeri menstruasi; mempercepat pengeluaran darah sehingga masa menstruasi menjadi lebih pendek (Sherwood, 2012); salah satu faktor risiko nyeri menstruasi adalah masa mentruasi yang panjang (Sinclair, 2010). Lanjut menurut Kural et al (2015) bahwa terdapat hubungan bermakna antara durasi menstruasi dan intensitas nyeri menstruasi, reponden yang durasi menstruasi > 5 hari lebih tinggi intensitas nyeri dibandingkan pada responden durasi menstruasi $\leq 5$ hari $(\rho 0,005$; OR 1,9).

Berman\& Snyder (2012) menjelaskan bahwa aliran darah dan metabolisme meningkat saat latihan peregangan yang merupakan salah satu faktor mengurangi gejala ketidaknyamanan fisik. Hasil penelitian ini sejalan dengan Sinclair (2010) dan Renuka \& Jeyagowri (2015) bahwa latihan peregangan (perut, pelvis, paha) dapat menekan kadar prostaglandin, kontraksi uterus yang sangat kuat menjadi berkurang sehingga nyeri berkurang. Semakin cepat kadar prostaglandin menurun semakin cepat pula nyeri hilang yang berarti durasi menjadi lebih pendek. Latihan peregangan meningkatkan vasodilatasi dan mengurangi iskemik, meningkatkan oksigenasi dan cairan ke uterus, mengeluarkan endorphin sehingga nyeri berkurang, memperbaiki sirkulasi di spinal dan sendi-sendi, relaksasi otot-otot uterus dan mempertahankan "nada" perut yang baik.

Peneliti menyimpulkan bahwa latihan peregangan perut dapat mengurangi durasi dysmenorrhoea karena dapat mengendalikan pengeluaran prostaglandin yang berlebihan yang berdampak pada penurunan kontraksi uterus yang terlalu kuat sebagai penyebab utama dysmenorrhoea primer dan mempercepat penyelesaian proses menstruasi. Selain itu, meningkatkan pengeluaran endorphine yang menyebabkan kenyamanan fisik dan mental meningkat.

\section{Radiasi Nyeri Menstruasi}

Berdasarkan analisis distribusi frekuensi menunjukkan proporsi tertinggi radiasi nyeri menstruasi pada kedua kelompok adalah beradiasi hanya pada satu area. Area radiasi terbanyak pada kelompok perlakuan adalah kemaluan, baik sebelum sebesar 56,10\% maupun setelah latihan sebesar $36,59 \%$ peregangan perut, selanjutnya area bokong, punggung, paha. Sedangkan pada kelompok kontrol area radiasi terbanyak adalah bokong kemudian punggung, kemaluan dan paha.

Hasil temuan ini sejalan dengan penelitian Kural et al (2015) berdasarkan analisis univarit terkait nyeri menstruasi dari perut bawah (34\%) radiasi ke kemaluan $(22,8 \%)$, punggung bawah (16\%), paha $(3,4 \%)$ dan menjawab "semua" $24 \%$. Odmivar et al (2015) menambahkan bahwa lebih dari satu area nyeri dan nyeri punggung bawah berhubungan erat dengan nyeri hebat, nyeri hanya di perut bawah $(50,8 \%)$, menyebar ke punggung bawah (18,4\%), pinggang $(7,7 \%)$, lain-lain $(23,1 \%)$. Lewis et al (2011) menjelaskan bahwa 
Faletehan Health Journal, 7 (1) (2020) 1-11

www. journal.Ippm-stikesfa.ac.id/ojs/index.php/FHJ

ISSN 2088-673X | 2597-8667

radiasi nyeri menstruasi yang paling sering adalah punggung bawah dan paha atas.

Nyeri pada saat menstruasi termasuk kategori nyeri viseral dalam yaitu nyeri akibat stimulasi organ-organ dalam internal (peluruhan dinding endometrium, pembuluh darah pecah, perdarahan). Nyeri viseral pada umumnya bersifat nyeri alih (persepsi nyeri pada daerah yang tidak terkena), sensasi nyeri meluas (radiasi) dari tempat awal cedera (endometrium) ke bagian tubuh yang lain. Stimulasi kuat pada serabut cabang visceral dapat mengakibatkan vasodilatasi dan nyeri pada area tubuh yang berkaitan dengan serabut tersebut. Uterus terletak di rongga pelvis mayor, ditutupi oleh peritoneum (lapisan perut), dikelililingi oleh otot perut bawah, supra pubik, otot vagina, paha dalam, lumbosakralis (punggung bawah), otot gluteal (bokong) (Reeder et al, 2014).

Hasil uji wilcoxon menginterpretasikan terdapat perbedaan radiasi nyeri menstruasi yang bermakna sebelum dan setelah latihan peregangan perut pada kelompok perlakuan. Hal ini berarti latihan peregangan perut mempunyai pengaruh mengurangi radiasi nyeri menstruasi pada remaja awal dibuktikan dengan 70,73\% menurun, $29,27 \%$ tetap dan tidak ada yang meningkat. Tidak ada perbedaan yang bermakna ditemukan pada kelompok kontrol ( $\rho$ value 0,291 ).

Menurut teori nyeri, prostaglandin yang dilepaskan dari endometrium merupakan salah satu mediator kimiawi yang mengaktifkan respons nyeri.Transmisi stimulus nyeri berlanjut di sepanjang serabut saraf aferen sampai transmisi tersebut berakhir di bagian kornu dorsalis medulla spinalis, di dalam kornu dorsalis substansi $\mathrm{P}$ (neurotransmitter) dilepaskan sehingga menyebabkan transmisi sinapsis ke saraf traktus spinothalamus. Hal ini memungkinkan impuls nyeri ditransmisikan lebih jauh ke dalam sistem saraf pusat otak sehingga nyeri dapat dipersepsikan. Pada jalur transmisi nyeri terdapat serabut-serabut di traktus spinotalamus yang berakhir di otak tengah dan kornu dorsalis dari medulla spinalis yang disebut sebagai "sistem kontrol desenden" Latihan yang terus menerus dan dilakukan dengan menyenangkan, maka otak mengeluarkan endorphin (opiat endogen) ke dalam sistem kontrol desenden dan berikatan dengan reseptor opiat di ujung serat nyeri aferen. Pengikatan ini menekan pelepasan substansi $\mathrm{P}$ sehingga transmisi lebih lanjut sinyal nyeri dihambat (Sherwood, 2012).

\section{Irama Nyeri Menstruasi}

Analisis univariat pada pengukuran pertama (pra-tes) menunjukkan mayoritas (97,6\%) responden pada kelompok perlakuan mempunyai irama nyeri menstruasi hilang timbul dan 3,4\% terus menerus sedangkan sebagian besar juga terjadi pada kelompok kontrol. Pengukuran kedua (pasca-tes) pada kelompok perlakuan menunjukkan tidak ditemukan lagi irama nyeri menstruasi yang terus menerus, sedangkan pada kelompok kontrol terjadi penurunan 5\% (2 responden) irama nyeri terus menerus.

Analisis bivariat menunjukkan secara statistic tidak ada perbedaan irama nyeri menstruasi yang bermakna sebelum dan setelah latihan peregangan perut, namun terjadi penurunan proporsi irama nyeri terus menerus yang dianggap lebih berat menjadi irama nyeri yang hilang timbul. Hasil studi Kural et al (2015) mendukung hasil penelitian ini yang juga menemukan 68\% dari 310 responden mengalami nyeri menstruasi secara spasmodic (tidak teratur). Nyeri pada supra pubik saat menstruasi dirasakan "tajam" dan "intermitten" (hilang timbul).

Faktor yang memungkinkan tidak ditemukan perbedaan bermakna karena hanya satu responden dengan irama nyeri terus menerus pada kelompok perlakuan sehingga perlu diteliti lanjut dengan responden fokus pada irama nyeri menstruasi yang terus menerus.

\section{Kualitas Nyeri Menstruasi}

Kualitas nyeri adalah kata-kata yang dibuat untuk mendeskripsikan sensasi nyeri yang dirasakan individu misalnya sensasi tertusuktusuk, teriris, terbakar, diremuk, ditekan, dan lainlain. Kualitas nyeri yang diteliti adalah jumlah dan jenis sensasi yang dirasakan.Hasil analisis univariat ditemukan mayoritas ( $\geq 90 \%)$ hanya satu sensasi yang dialami kedua kelompok responden. Tiga jenis sensasi terbanyak pertama adalah "ditusuk-tusuk", kedua adalah sensasi“ditekan", dan ketiga adalah sensasi "diremuk".

Reeder et al (2014) menjelaskan bahwa dysmenorrhoea primer dapat berupa nyeri tajam, dalam, kram, atau tumpul. Hasil penelitian ini sejalan dengan Odmivar et al (2015) yaitu penelitian tentang kualitas dysmenorrhoea dari 1000 partisipan usia 11-28 tahun, ditemukan 
97,2\% responden mengalami satu sensasi nyeri menstruasi, namun jenis sensasi terbanyak adalah sensasi diremuk $(63,1 \%)$, sensasi ditusuk $(20 \%)$, sensasi tersengat $(14,1 \%)$, sensasi campur $(2,8 \%)$. Kural et al (2015) menjelaskan bahwa dari 310 responden ditemukan sensasi tembak $(15,4 \%)$, sensasi tajam teriris $(11,9 \%)$, sensasi ditusuk $(4,7 \%)$, sensasi tidak spesifik (68\%). Studi Gulzar et al (2015) mempertegas subjektivitas terkait kualitas nyeri menstruasi yaitu dengan menyeleksi variable predictor nyeri menstruasi menggunakan multiple binary logistic regression, diperoleh hasil yang bermakna ( $\rho$ 0,05) adalah persepsi responden yang mengatakan bahwa nyeri menstruasi adalah nyeri pembunuh.

Analisis Bivariat uji Wilcoxon menunjukkan tidak ada perbedaan kualitas nyeri yang bermakna sebelum dan setelah latihan peregangan perut pada kedua kelompok responden. Hal ini berarti latihan peregangan perut tidak berpengaruh dalam menurunkan kualitas nyeri.

Peneliti belum menemukan penelitian terdahulu yang terkait hasil penelitian ini. , namun secara konsep teori bahwa nyeri menstruasi termasuk nyeri visceral dan nyeri alih. Berman \& Snyder (2012) menjelaskan bahwa nyeri visceral digambarkan sebagai sensasi tajam, tumpul, kram, berdenyut, ditekan, diremuk, meregang, terbakar, tersengat atau unik tergantung organ yang terlibat. Nyeri visceral sangat subjektivitas, tidak terdapat perbendaharaan kata nyeri yang khusus atau umum. Sumber atau tempat proses persepsi adalah sama yaitu di korteks serebri (Sherwood,2012). Sensasi nyeri yang klien rasakan seringkali tidak dapat dijelaskan.Tingkatan sensasi nyeri sulit diukur, misalnya apakah sensasi tajam lebih tinggi dari pada sensasi tumpul atau sebaliknya. Semua itu tergantung dari persepsi dan pengalaman nyeri individu yang berbeda-beda, oleh karena itu perlu penyamaan persepsi nyeri ketika akan dievaluasi. Kualitas dan jenis sensasi dysmenorrhoea responden menurun atau hilang seiring dengan terhentinya menstruasi atau durasi menstruasi yang memendek.

\section{Simpulan}

Latihan peregangan perut menurunkan durasi dan radiasi nyeri menstruasi secara bermakna dengan menekan kadar prostaglandin dan meningkatkan pengeluaran endorphin yang mempengaruhi penurunan nyeri menstruasi.

\section{Referensi}

Agarwal,A. \& Venkat.A. (2009). Questionare study on Menstrual disorders in adolescent girls in Singapore.J Pediatr. Adolesc.Gynecol,22, 365-371.

Berman,A \& Snyder,S. (2012). Fundamentals of nursing: concepts, process \& practice. Vol.1, ninth edition. New Jersey. Pearson education Inc

Blakey,H et al. (2010). Is exercise associated with primary dysmenrrhea in young women ?BJOG.2010; 117:222-4 (PubMed).

Bulechek, G.M et al. 2013. Nursing Intervention Classification (NIC).Sixth edition. St. Louis Missouri. Elsevier Mosby.

Dahlan, M.S. (2015). Statistic untuk Kedokteran dan Kesehatan: Metode MSD. Jakarta. Epidemiologi Indonesia.

Gamit,K.S., Sheth,M.S., Vyas.N.J.(2014). The effect of stretching exercise on primary dysmenorrheal I adult girls. International Journal of Medical Science and Public Health.2014,vol.3 Issue 5; 549-551

Gulzar,S et al. (2015). Prevalence, Perceptions and Effect of Dysmenorrhea in School Going Felame Adolescents of Karachi, Pakistan.International Journal of Innovative Research \& Development. 2015, Vol 4 Issue 2; 236-240

Kazama et al. (2015).Prevalence of dysmenorrheal and its correlating lifestyle factors in Japanese female junior high school students.Tohoku J. exp.Med.2015. June:236(2):107-13

Karampour,E\& Ebrahim,K. (2012). The influence of stretch training on primary dysmenorrheal, advances in environmental biology. 2012. Vol 6 (12) 3069-3071

Kural,M.R et al. (2015). Menstrual characteristics and prevalence of dysmenorrheal in college going girls. Journal of family medicine and primary care.2015,Juli-Sept,4(3):426-431.

Lewis at al. (2011). Medical Surgical nursing. Eighth edition. International edition. Elseiver Mosby. USA

Omidvar,S., Bakouei,F., Amiri,F.N., Begum,K. (2015). Primary dysmenorrheal and Menstrual Symptoms in Indian Female students: Prevalence, Impact and Management. Global Journal of health Science; Vol.8,No.8;2016. ISSN 1916-9736 
Faletehan Health Journal, 7 (1) (2020) 1-11 www. journal.Ippm-stikesfa.ac.id/ojs/index.php/FHJ ISSN 2088-673X | 2597-8667

Osayande,A.S\& Mehaulic, S (2014). Diagnosis and Initial management of dysmenorrheal. American Family Phisician.89 (5): 341-6

Ozerdogan N., Sayiner.D.,Ayranci., Unsal.A. (2009). Prevalence of Dysmenorrhea among students at a University in Turkey. International Journal of Gynecology and Obstetrics.2009; 107(1):39-43

Proverawati \& Maisaroh.(2009). Menarch.Yogyakarta.Nuha medika.

Rajalaxsmi,V., Kumar,G.M., Veena,S .(2015). A Study Analize the effecttveness of Core Strengthening Exercise and Stretching Program for Young Female Physiotherapy Students with Primary Dysmenorrhea. International Journal of Physiotherapy \& Occupational Therapy.Vol 2. Issue 1, June 2016,27-32

Reeder,S.J., Martin,L.L., Griffin,D.K. (2014). Maternity Nursing: Family, Newborn, and women'n health Care. $18^{\text {th }}$ ed. USA.Lippincott Williams and Wilkins Inc.

Renuka,K., Jeyagowri,S. (2014). Stretching exercise therapy and Primary Dysmenorrhea
Nursing Perspectives.IOSR Journal of Nursing and Health Science.e-ISSN: 23201959. Vol.4 Issue 3 Ver.III (May-Jun,2015): pp01-04

Shahr-jerdy, Hosseini RS.(2012). Effect of stretching exercise on primary dysmenorrheal in adolescent girls. Biomedical Human Kinetics, 2012;4:127-32

Sherwood,L. (2012). Fisiologi manusia: dari sel ke system. Edisi 6. Jakarta. EGC

Sinclair,C. (2010). Buku saku kebidanan. Jakarta. EGC.

Snyder \& Lindquist. (2010). Complementary \&Alternative : Therapies in Nursing. Sixth edition. New York. Springer Publishing Company.

Thermacare.(2010). Abdominal Stretching Exercise for menstrual pain. http//www.chiromax.com

Unsal,A et al. (2010). Prevalence of dysmenorrheal and its effect on quality of life among a group of female university students. Ups Journal of Medical Science.2010;115(2):138-45 